\title{
Comparative Study on Performance Improvement of SPWM/THIPWM based DCMLI Grid Connected DFIG
}

\author{
Ahmed A Hossam-Eldin ${ }^{1}$, Emtethal Negm $^{1}$, Mohamed $\mathrm{S}$ Elgamal ${ }^{2}$ and Kareem M AboRas ${ }^{1}$ \\ ${ }^{1}$ Electrical Department, 21500 Alexandria University, Egypt \\ ${ }^{2}$ Manager Of Operation Services Department, 21532 Sumed Alexandria, Egypt
}

\begin{abstract}
Multi-level voltage source converter is integrated in various fields in renewable energy power generation technologies such as wind and solar sources for applications that need higher voltage and higher power. In wind power generation market, doubly fed induction generator (DFIG) based on wind power generation is now the leading technology as they are economically feasible, they do offer a variable speed and efficient substitute to the fossil fuel. This paper proposes a DFIG based on a back to back diode clamped multilevel converter systems (DCMLI) fired comparatively by sinusoidal pulse width modulation (SPWM) and third harmonic injection pulse width modulation (THIPWM) techniques. By using these technologies, the DFIG performance is compared for different wind speeds under normal operation condition. The proposed approach shows that the DCMLI systems generate a near sinusoidal voltage with lower values in total harmonic distortion (THD) thus, upgrading the power quality that is produced by DFIG. Lastly, the variation of frequency of induced rotor voltage and the active power flow due to the wind speed changes when the rotor speed changes from super synchronous to sub synchronous speeds is investigated.
\end{abstract}

\section{Introduction}

Meanwhile the last three decades, the resources of renewable energy are strongly penetrated into the conventional grid of power system. The generation of wind energy has always existed and will keep to display its crucial existence in the near future. The power system operators and planners have an enormous challenge to assure stability, security and reliability in power supply with a significant contribution of wind energy conversion system (WECS) power plants. The capacity power range of the large wind turbines is from 3 to 12 MW. Most types of wind turbines are the type of variable-speed operation through utilizing a doubly fed induction generator (DFIG) with the pitch control technique or a synchronous generator which doesn't have gearbox connection.

The variable-speed WECS based on DFIG amount is almost fifty percent of the total number of all globally installed wind turbines. This is because they have obvious features as follow, lower cost, the back to back converters power rating is lower, speed span is wide, independent power control, and lower power losses [1]. The DFIG is able to be operated in two different modes: sub-synchronous mode or super synchronous mode due to the converters have bi-directionally power flow ability.

The DFIG is connected directly to the grid via the three phase stator winding. As well as the rotor is connected to the grid via back to back voltage source converters "grid side converter (GSC) and rotor side converter (RSC)". The converters are linked via a DC bus of coupling capacitor $[2,3]$. The converter power rating is about 20 to $30 \%$ from rated capacity of DFIG.

In the presented paper a WECS based on a back to back diode-clamped multilevel converter systems (DCMLI) fired comparatively by SPWM and THIPWM techniques are proposed. A comparative study on the wind turbine system based on a DCMLI fired by SPWM has been carried out for different wind speed profile at normal condition case. Also, the variation of frequency of induced rotor voltage and the active power flow due to the variation in wind speed according to the rotor speed changes from super synchronous to sub-synchronous speeds are considered in the next section.

\section{The principle of multi-level inverter}

By means of using multi-level voltage source converter technology, it is now possible to acquire the higher voltage with standard power rating components and nearly pure signal for voltage and current signals. Further, the filters size and cost are also reduced by integrating multilevel technology. Multilevel inverters have been commonly used in WECS because voltage stress on switching devices of multilevel converters are lower, reduced variations of active and reactive power, the operating switching frequency can be decreased, total harmonic distortion (THD) is lower, output current has very low distortions, and lower $\mathrm{dV} / \mathrm{dt}$ value $[3,4]$. This is obtained by using the arrangement of more switches than what is utilized in the two-level converters. 


\section{Asynchronous DFIG Wind Power Generator Grid Connected System}

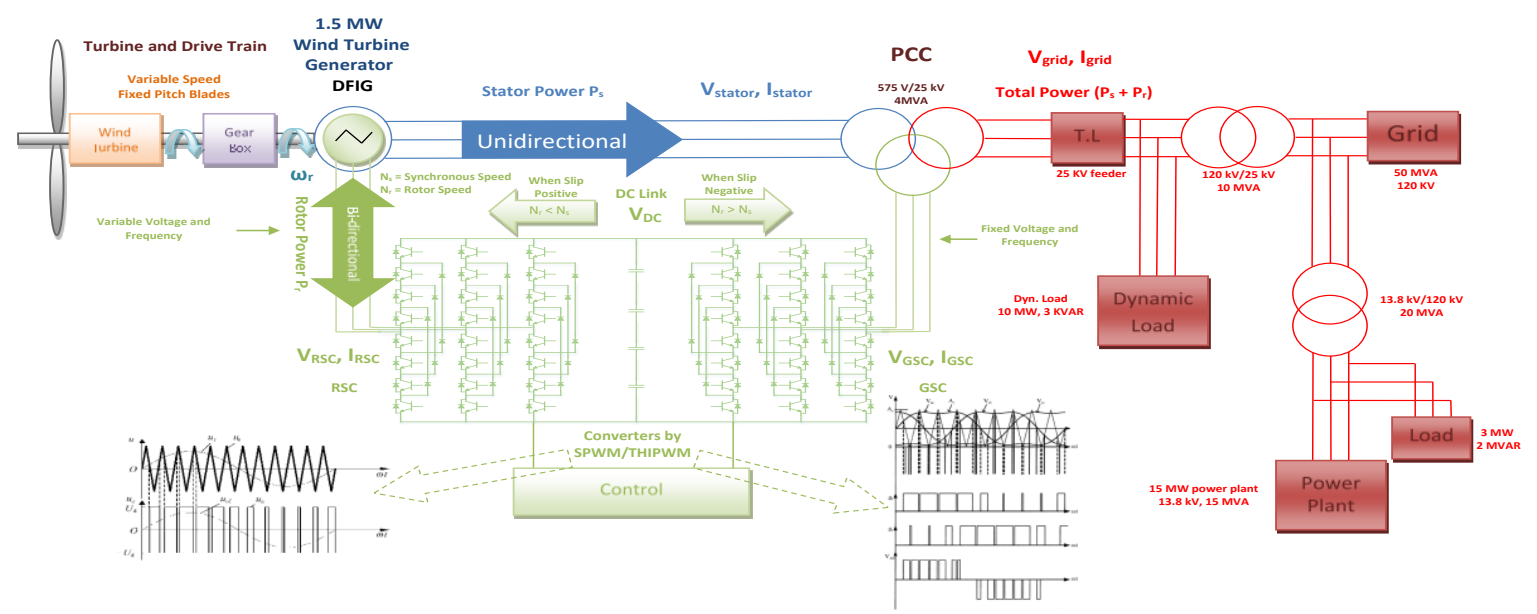

Fig. 1. Doubly Fed Induction Generator based on Wind Energy Converter System.

There are many types of multilevel inverters topologies existing, such as: Diode Clamped multilevel inverters, Flying Capacitor multilevel inverters and Cascaded H-bridge multilevel inverters [5-8].

The variation in wind speed changes DFIG rotor speed which results to changing in the rotor current frequency. A controllable frequency and magnitude of rotor voltage can be injected to the three-phase DFIG rotor circuit, therefore a three-phase voltage source control is needed. In this study DCMLI with two, three, four and five level DCMLI are used. The main characteristics of this topology are: -The profile of its output waveform is nearly sinusoidal. -The whole capacitors have to be pre-charged at the beginning of the operation. -Output voltage level depends on the capacitor voltage. In order to keep the balancing of the three-phase output voltage, the equality of their capacitor is needed in this case [9]. In the system proposed, SPWM and THIPWM techniques have been implemented as shown in Fig. 1. The total voltage across all capacitors is DC voltage Vdc which is equal to $1150 \mathrm{~V}$. Each switching device has a limited voltage stress across it which is equal to Vdc via the clamping diodes. An $\mathrm{n}$ level inverter needs 2(n-1) switching devices, (n-1) (n-2) diodes, and (n-1) voltage sources or capacitors [10, 11]. The five-level DCMLI is illustrated in Fig. 2. The capacitors C1, C2, C3 and $\mathrm{C} 4$ are series connected. These capacitors are used to split the DC-bus voltage into five levels where the voltage across all capacitors are equal to $1150 \mathrm{~V}$, each capacitor is $50 \mathrm{mF}$ and their total capacitance equals 10 $\mathrm{mF}$ for five-level converter case.

Additionally, four complementary pairs of switches that are set so that when a switch is turned $\mathrm{ON}$, its complementary pair is turned OFF for each phase. The complementary switch pairs for phase leg A are (S1, S5), (S2, S6) and so on. Furthermore, the switches in a diodeclamped inverter that are switched $\mathrm{ON}$ for a phase leg are always in series and adjacent as it is shown in Table 1. The five-levels of output voltage Van are denoted as $\mathrm{Vdc} / 2, \mathrm{Vdc} / 4,0,-\mathrm{Vdc} / 2$ and $-\mathrm{Vdc} / 4$ as it is shown in Table 1 where Vdc is equal to $1150 \mathrm{~V}$ in the system. To obtain the voltage level $\mathrm{Vdc} / 2$, the switches $\mathrm{S} 1, \mathrm{~S} 2, \mathrm{~S} 3$ and $\mathrm{S} 4$ are to be switched ON. Similarly, to obtain the voltage level $-\mathrm{Vdc} / 2$ and 0 , the switches (S5, S6, S7, S8) and (S3, S4, S5, S6), are to be switched ON correspondingly as it is shown in Table 1 . The switching states in one leg of a five-level DCMLI are shown in Table 1. The switches S1, S2, S3, S4, S5, S6, S7 and S8 are IGBT's switches which have rating power $500 \mathrm{kVA}$ equal to $30 \%$ of the DFIG rating power. Each blocking diode and the active switches have the same voltage rating, diodes will be required an ' $m$ ' number of diodes in series. Similarly, for each phase the required number of diodes would be $(\mathrm{m}-1) \times(\mathrm{m}-2)$. Therefore, the blocking diodes number in a DCMLI is linked to the levels number quadratically. The five-level diode clamped inverter are diodes D1, D1', D2, D2', D3 and D3'. These six diodes help in clamping the switching voltage to half of the DC bus voltage.

Table 1. Switching states of 5-level DCMLI in one leg.

\begin{tabular}{cccccccc}
\hline $\begin{array}{c}\text { Output } \\
\text { voltages }\end{array}$ & $\mathrm{S}_{1}$ & $\mathrm{~S}_{2}$ & $\mathrm{~S}_{3}$ & $\mathrm{~S}_{4}$ & $\mathrm{~S}_{5}$ & $\mathrm{~S}_{6}$ & $\mathrm{~S}_{7}$ \\
\hline $\mathrm{V}_{\mathrm{dc}} / 2$ & 1 & 1 & 1 & 1 & 0 & 0 & 0 \\
$\mathrm{~V}_{\mathrm{dc}} / 4$ & 0 & 1 & 1 & 1 & 1 & 0 & 0 \\
0 & 0 & 0 & 1 & 1 & 1 & 1 & 0 \\
$-\mathrm{V}_{\mathrm{dc}} / 4$ & 0 & 0 & 0 & 1 & 1 & 1 & 1 \\
$-\mathrm{V}_{\mathrm{dc}} / 2$ & 0 & 0 & 0 & 0 & 1 & 1 & 1 \\
\hline
\end{tabular}

During the past decades, SPWM has been used greatly in control applications of AC motors. In this method, the three-phase signals of modulating reference are compared with a common signal of triangular carrier. Therefore, from their intersections points the firing signal of power switching devices of the converter are determined. However, this method cannot use the full voltage of supply in the inverter and has high harmonic distortion in the produced waveform of output voltages because the SPWM characteristics of switching are not of a symmetrical nature. 


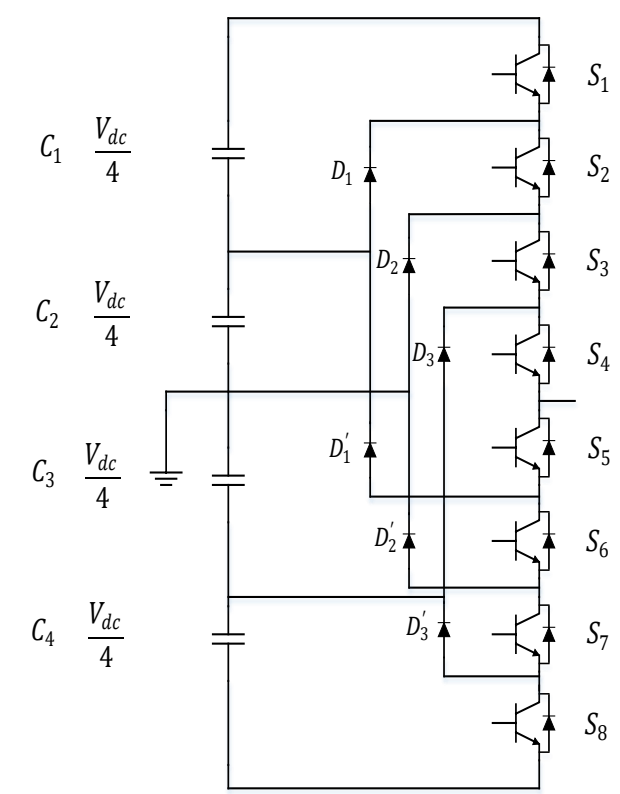

Fig. 2. One leg of five-level DCMLI.

THIPWM is a modified technique for generating modulation signals, and it has a lot of features such as: reduction in the losses of commutation, greater modulation index amplitude, higher utilization of the DCbus voltage and reduction in the total harmonic distortion (THD) of the waveform of output voltages, compared with the SPWM technique [12-18].

A modulation signal, a carrier-based SPWM and THIPWM techniques are applied to four-level DCMLI by comparing reference waveform signal with the triangle carrier signal and the voltage across the three upper switches in phase $\mathrm{c}$ as shown in Fig. 3 and Fig. 4. Those techniques have been utilized to study the effect of a multi-level inverter (MLI) on power quality of wind energy.

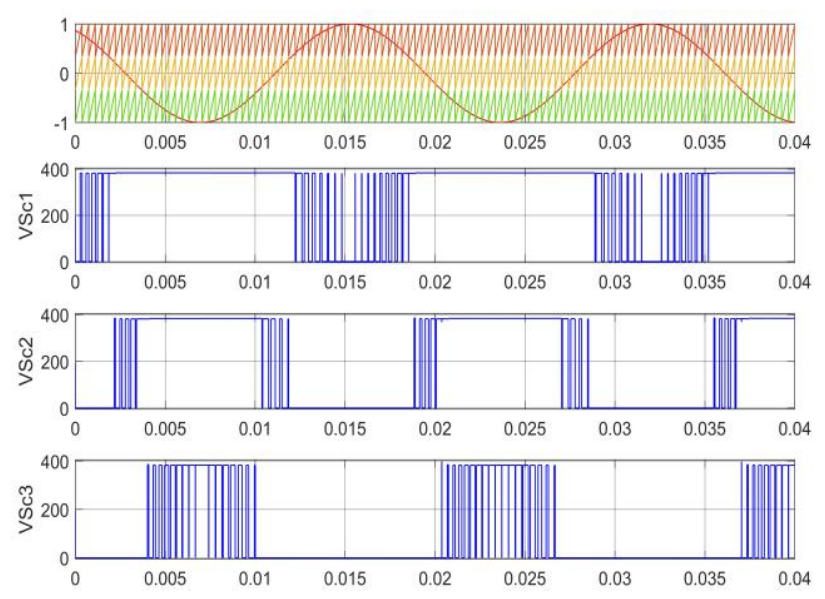

Fig. 3. Modulation signal of SPWM four-level DCMLI.

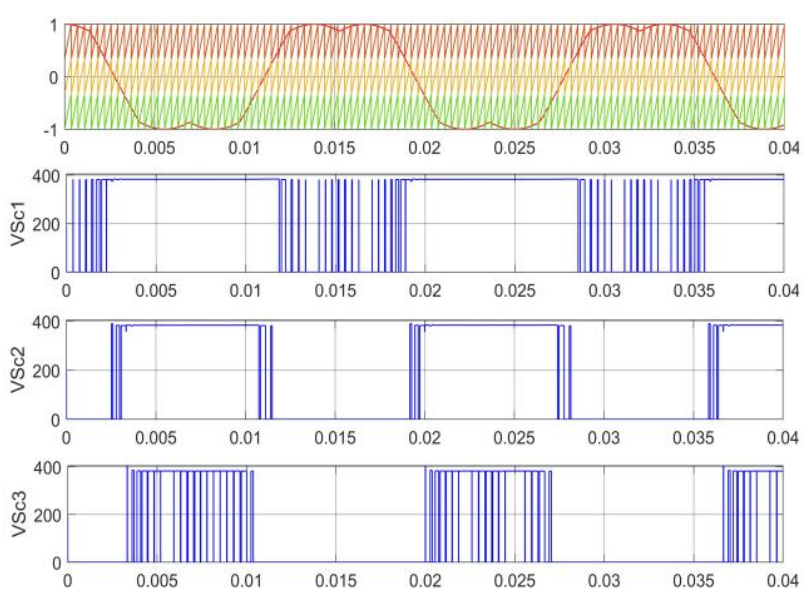

Fig. 4. Modulation signal of THIPWM four-level DCMLI.

\section{The model of power grid}

The presented paper adopts the DFIG which has 1.5 MW capacity with vector control [19-21], DFIG based on WECS is built in MATLAB. The DFIG is connected using $575 \mathrm{~V} / 25 \mathrm{kV}$ transformer to a $25 \mathrm{kV}$ bus. $25 \mathrm{kV}$ bus is connected to $120 \mathrm{kV}$ grid through $25 \mathrm{~km}$ line feeder. The grid consists of $25 \mathrm{kV} / 120 \mathrm{kV}$ transformer, a $150 \mathrm{MW}$ power plant with $13.8 \mathrm{kV}$ generator with step-up transformer $13.8 \mathrm{kV} / 25 \mathrm{kV}$. In DFIG, the stator is directly connected to the grid and a back to back MLI fired by SPWM and THIPWM techniques in the circuit of the rotor which initiate the link between rotor and grid sides. Back to back MLI are coupled by the capacitor in a DClink of $10 \mathrm{mF}$ as illustrated in Fig 1. No further control is applied to pitch angles in vector control, so the paper studies only the effect of the DCMLI on the THD of DFIG voltage and current. The case of wind variation is studied in three steps: $12 \mathrm{~m} / \mathrm{s}$ from zero to 2 second, 9 $\mathrm{m} / \mathrm{s}$ from 2 second to 8 second and $12 \mathrm{~m} / \mathrm{s}$ from 8 second to 19 second as shown in Fig. 5.

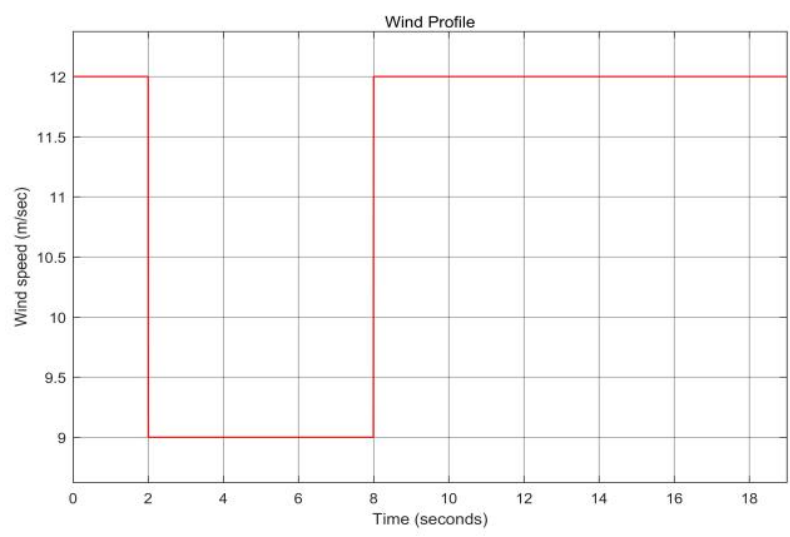

Fig. 5. DFIG variables for two different step values in wind speed. 


\section{Simulation results and discussions}

From the result it is found that the five-level multilevel diode clamped SPWM converter and the four level THIPWM have the optimum result and meet the IEEE std 519 limits. Now the full detailed simulation data are presented for the vector control for the WECS based on DFIG with 5-level SPWM diode clamped converter. The vector control is divided into GSC and RSC control [22$23]$.

In the presented system showing THD and performance in output voltage and current for the two, three, four and five level types of SPWM converters compared at different operating points in the system as shown in Table 2 and pointed in Fig. 1 for wind speed 12 $\mathrm{m} / \mathrm{s}, 9 \mathrm{~m} / \mathrm{s}$ and all of these results for the applied systems are achieved without installation of any static filters. Also, presents two, three and four level types of THIPWM converters and their THD in output voltage and current at different points have been illustrated in Table 2 .

A two-level DCMLI output fired by SPWM is showing that THD which is $16.2 \%$ is highly unacceptable THD value as illustrated in Table 2. Therefore, a fivelevel DCMLI fired by SPWM is used to improve the quality of the supply in the circuit of the rotor. The fivelevel DCMLI waveform of the output voltage is illustrated in Fig. 6. It is clear that DCMLI fired by SPWM is injecting the same magnitude value of output voltage. However, it is improving the quality of output voltage. THD has reduced vastly to $3.21 \%$ and it is shown in Fig. 7. A two-level inverter output by THIPWM in Table 2 shows that THD is found $11.56 \%$ at $12 \mathrm{~m} / \mathrm{s}$ wind speed which is highly unacceptable but, it is lower than two-level inverter output by SPWM. The four-level inverter by THIPWM output voltage waveform has a value of THD at PCC equal to $4.39 \%$ is accepted according to IEEE std. The number of multi-level diode clamped levels needed in the technique THIPW is less than the number of multilevel converters by SPWM, four-level is only needed to get accepted THD value according to IEEE std in THIPWM instead of five-level in SPWM technique.

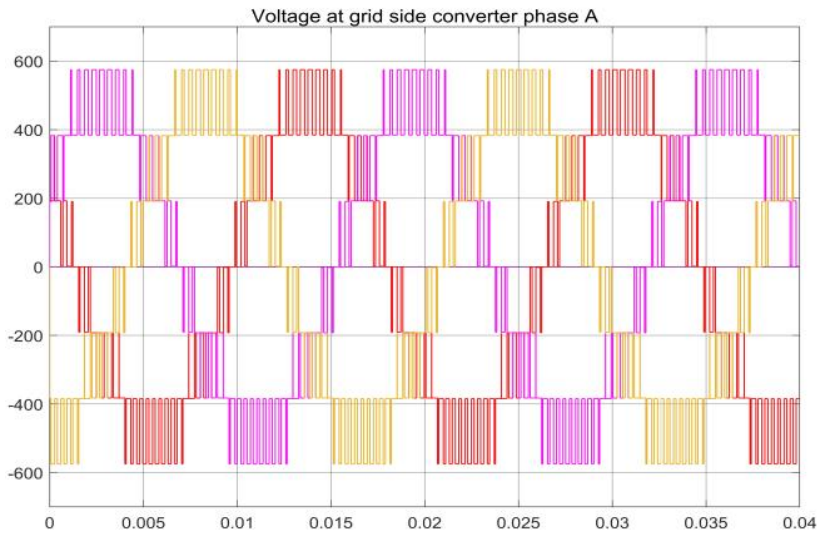

Fig. 6. Three phase voltage of MLI for five level.

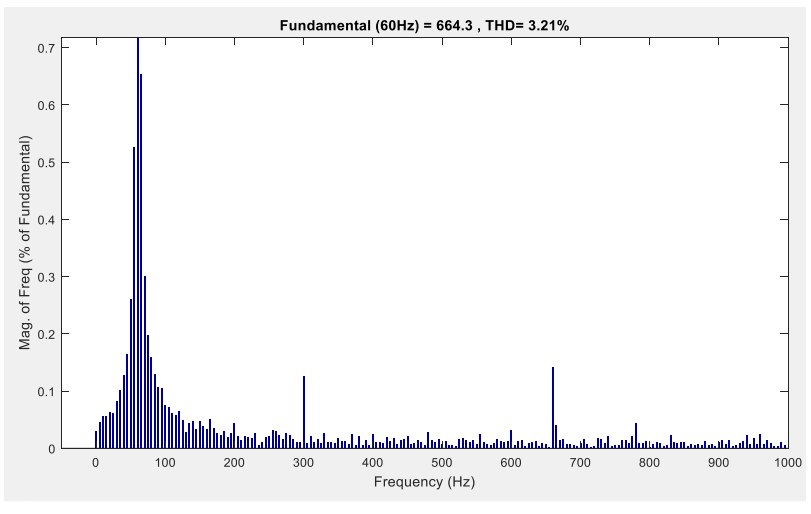

Fig. 7. Fast Fourier Transform (FFT) window.

Performance of DFIG due to wind speed variation in three variable steps pattern will appear as an effect on variation in active power, rotor speed and the frequency of induced rotor voltage according to the variation of the input wind speed. The DC link voltage performance is sustained constant at 1150 volts which is its reference value during the MW simulation as declared in Fig. 8. Furthermore, for rotor speed profile it is noticed that at 12 $\mathrm{m} / \mathrm{s}$ wind speed the rotor speed is in super-synchronous mode settles at $1.2 \mathrm{p} . \mathrm{u}$ and rotor speed starts to decrease. As a result, the mode turns to be under-synchronous when the wind speed decreased as it is illustrated in Fig. 9.

Table 2. Comparaison between DCMLI by SPWM from two level to five level and THIPWM from two levels to four levels in THD for voltage and current at Stator side at wind speed 12 and $9 \mathrm{~m} / \mathrm{s}$.

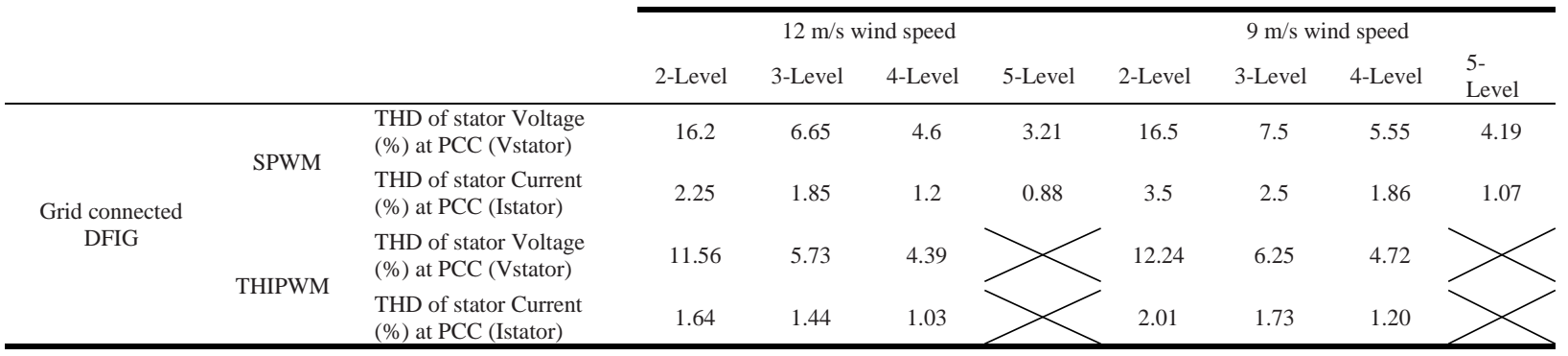


The other graphs in Fig. 10 (a) and Fig. 10 (b) show the root mean square (RMS) values of voltage and current (Vgrid, Igrid) at PCC after step up transformer $575 \mathrm{~V} /$ $25 \mathrm{kV}$ point. In addition, voltage in grid side converter (VGSC) is shown in Fig. 10 (c). The graphs show the effect of changing the wind speed from $12 \mathrm{~m} / \mathrm{s}$ to $9 \mathrm{~m} / \mathrm{s}$ and from $9 \mathrm{~m} / \mathrm{s}$ to $12 \mathrm{~m} / \mathrm{s}$ on voltage and current at these points as shown in Fig. 10.

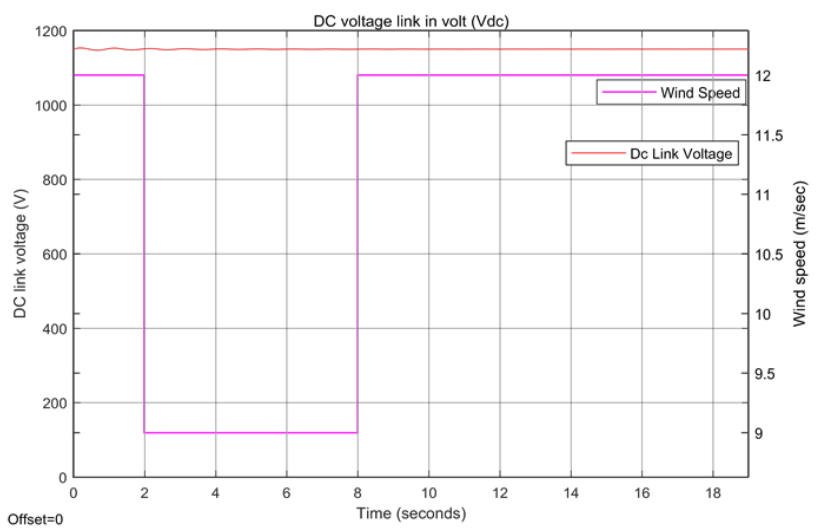

Fig. 8. DC link voltage across the capacitors.

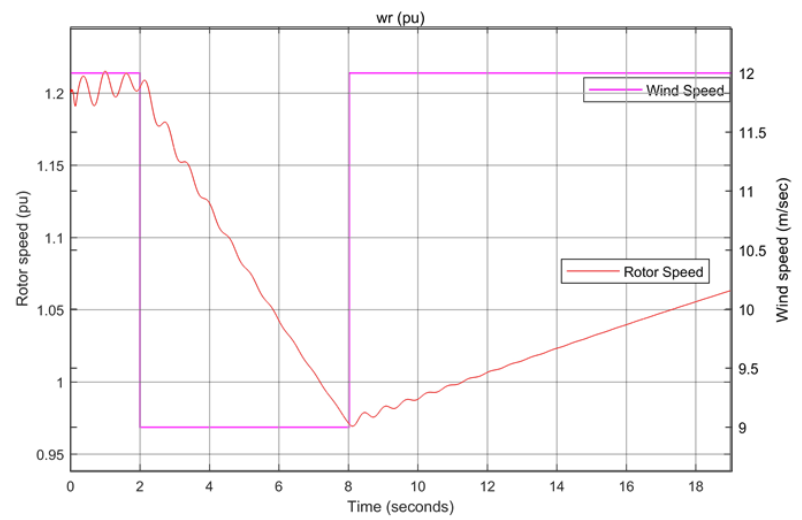

Fig. 9. Rotor speed and wind speed.

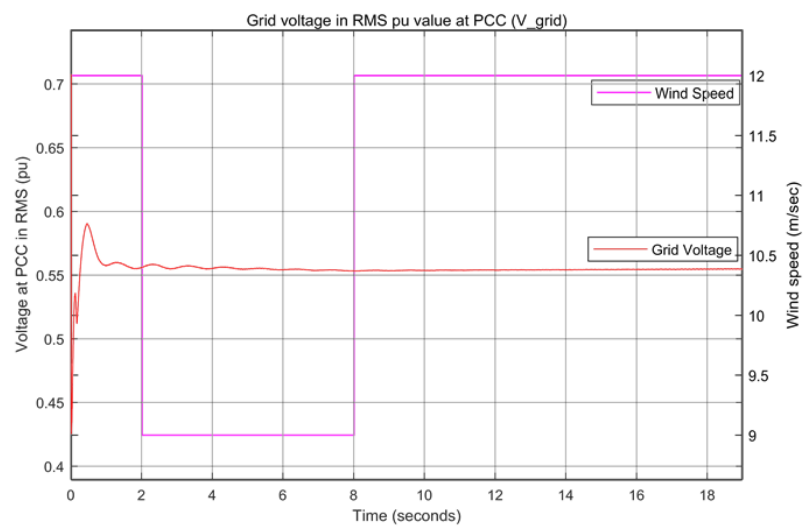

(a)

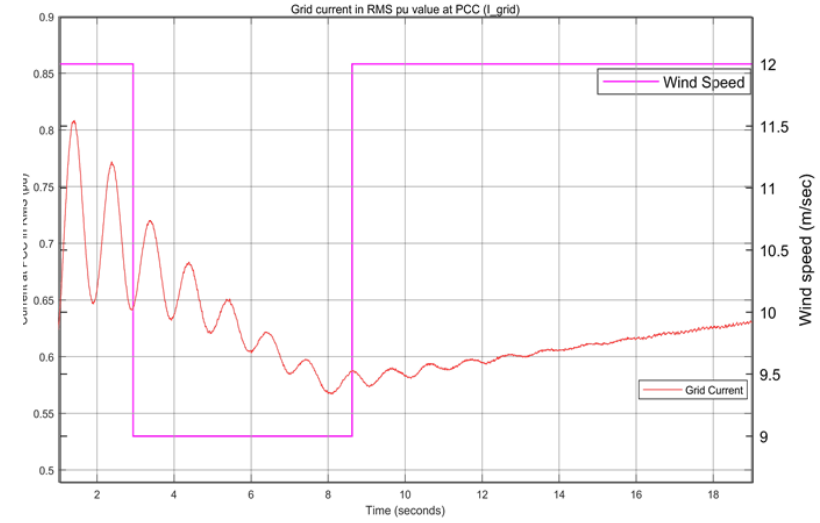

(b)

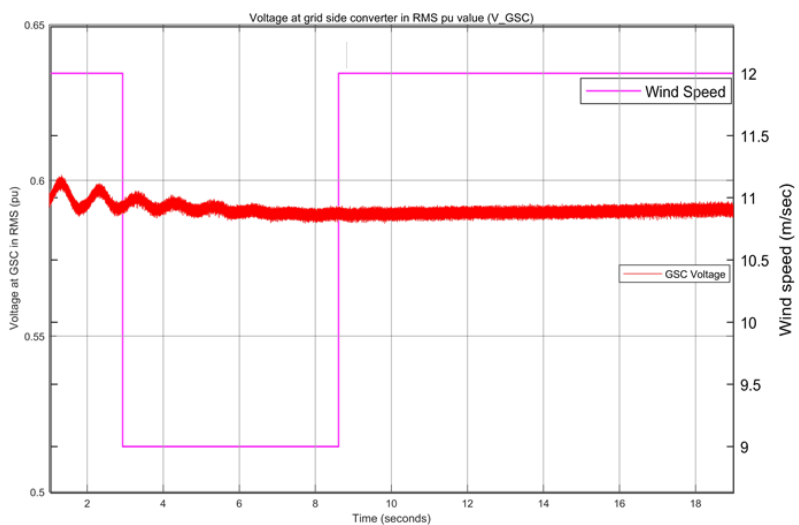

(c)

Fig. 10. (a) Grid voltage in RMS at PCC, (b) Grid current in RMS at PCC, (c) Voltage at GSC in RMS for two different step wind speed.

The active power flow is illustrated in Fig. 11 (a) at wind speed $12 \mathrm{~m} / \mathrm{s}$ and its direction from rotor side to grid. The active power flow at stator is shown in Fig. 11 (b). The total power from the wind system is the power from rotor side converter plus the power from the stator of DFIG with its rated value and all power flow in the same side drain to the grid as shown in Fig. 11 (c). When wind speed changed to $9 \mathrm{~m} / \mathrm{s}$, the active power flow is illustrated as shown in Fig. 11 and the active power flow symbols are mentioned in Fig. 1. The total active power from the wind system power "Ps-Pr" is decreased because the direction of active power flow at rotor side is reversed and became from grid to rotor side to compensate the decreasing in rotor speed and flux. Frequency of the voltage rotor side is increased to increase the frequency of the flux to maintain the active power constant at its rated value that is induced from stator of DFIG. 


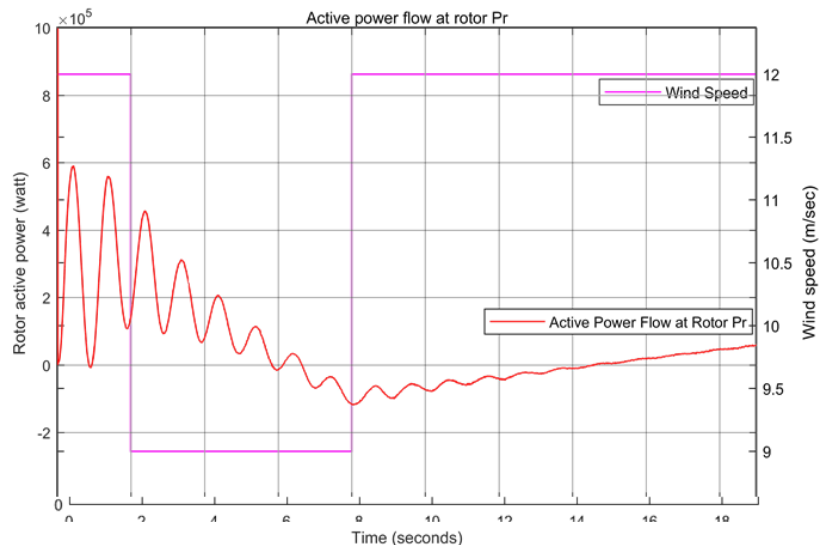

(a)

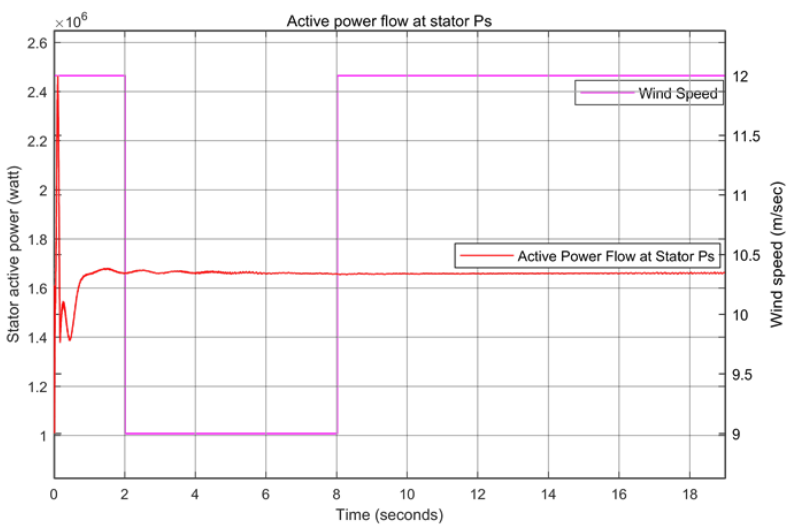

(b)

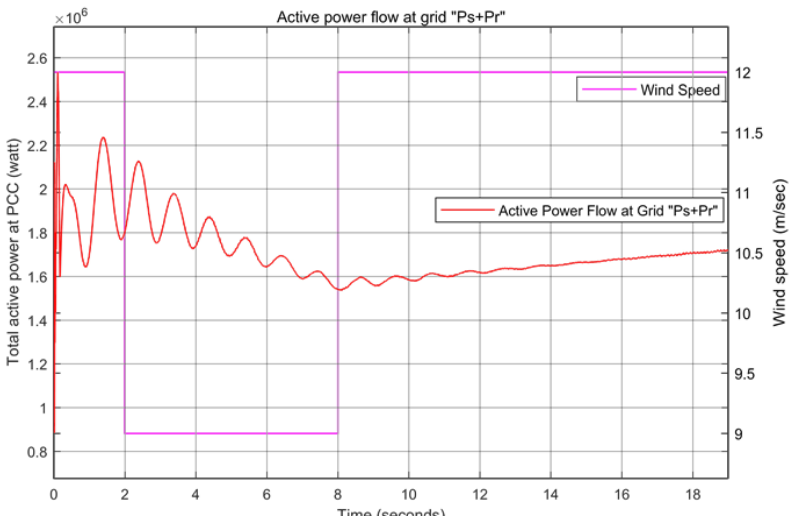

(c)

Fig. 11. (a) Active power flow at rotor, (b) Active power flow at stator, (c) Total active power flow at grid for two different wind speed wind speed.

Figure 12 illustrates the changing in frequency of induced rotor voltage. At $12 \mathrm{~m} / \mathrm{s}$ wind speed, the frequency reaches $27 \mathrm{~Hz}$ and when the wind speed decreased to $9 \mathrm{~m} / \mathrm{s}$, the frequency starts to increase at 2 second. The frequency increases due to compensating the decreasing in wind speed value that will affect and reduce the magnetic field applied in rotor, so the frequency increases as a result of active rotor power reversing its direction from the grid to rotor side to supply the shortage of magnetic flux.

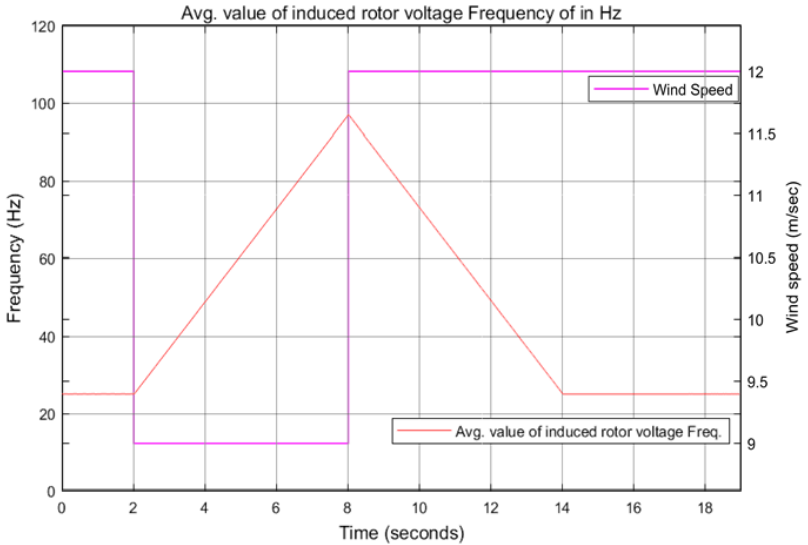

Fig. 12. Frequency of induced rotor voltage.

Here Fig. 13 shows a load sharing between the grid and wind turbine system for the dynamic load $10 \mathrm{MW}, 3$ MVAR power flow during the wind speed profile for the whole system as it is shown in Fig. 1. In Fig. 13 (a), shows a load sharing of active power flow from wind turbine to dynamic load and Fig. 13 (b) illustrates a load sharing of active power flow from grid to dynamic load. Table 3 shows the value of modulation index (MI) during the change of wind speed at five-level SPWM and fourlevel THIPWM in GSC.

Table 3. MI variation at GSC for 5-level SPWM and 4-level THIPWM.

\begin{tabular}{ccc}
\hline \multirow{2}{*}{ MI at GSC } & \multicolumn{2}{c}{ Wind speed $(\mathrm{m} / \mathrm{s})$} \\
& $12 \mathrm{~m} / \mathrm{s}$ & $9 \mathrm{~m} / \mathrm{s}$ \\
\hline 5-level SPWM & 0.66 & 0.65 \\
4-level THIPWM & 0.61 & 0.60 \\
\hline
\end{tabular}

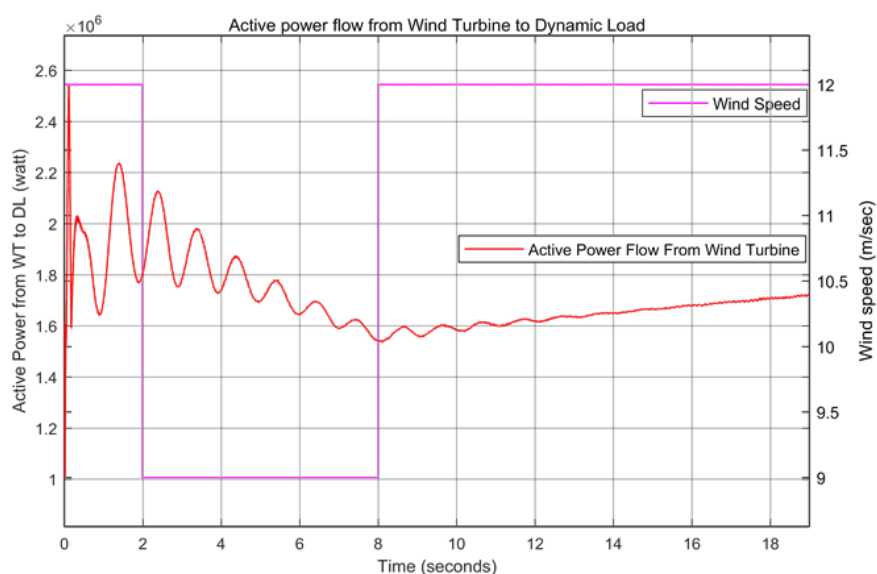

(a) 


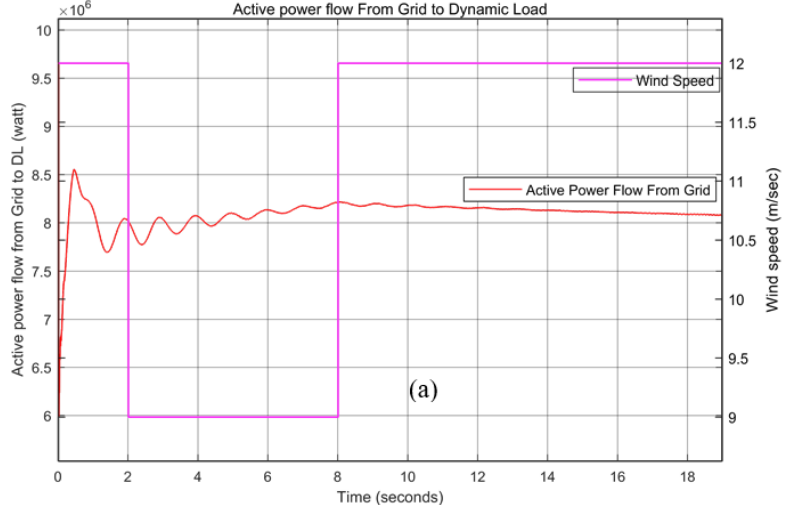

(b)

Fig. 13. (a) Load sharing of active power flow from wind turbine to dynamic load, (b) Load sharing of active power flow from grid to dynamic load.

\section{Conclusions}

The performance of a diode clamped multilevel inverter based vector controlled DFIG is investigated under different operating conditions. The main focus of that work is to use wind energy with minimal harmonic distortion levels under different speeds of wind energy without static filters intervention. A 5-level DCMLI using SPWM technique is capable to maintain voltage THD levels to $3.21 \%$ at normal operating conditions of $12 \mathrm{~m} / \mathrm{s}$ whereas THD levels does not exceed $4.19 \%$ at worst conditions of low wind speeds. A 4-level THIPWM based DCMLI is capable to maintain THD levels at normal wind speeds at $4.39 \%$ and at $4.72 \%$ at low wind speeds. The graphs showing the variation of rotor injected voltage frequency and active power flow during super-synchronous and sub-synchronous rotor speeds in response to wind speed variations show superior performance. The main contribution in the proposed model, in that research work, is a simulative study to the internationally well adopted DFIG grid interconnection using multilevel power electronics topology with the avoidance of using static filters and find out the number of levels that achieve the IEEE 519 criteria of THD which is less than $5 \%$ for both techniques. The study showed that the proposed approach using THIPWM or SPWM resulted in a superior performance in terms of THD mitigation in all modes of operating conditions. Comparative results were demonstrated and discussed with definite conclusions.

\section{References}

1. D. Zhou, G. Zhang, F. Blaabjerg, IEEE Transactions on Industry Applications, 54, 3637 - 3644 (2018).

2. M. Zhao, X. Yuan, J. Hu, IEEE Transactions on Power Systems,; 33, 1484 - 1495 (2018).

3. A. Hota, S. Jain, V. Agarwal, IEEE Transactions on Power Electronics, 32, 7414 - 7418 (2017).
4. C. Hsieh, T. Liang, S. Chen, S. Tsai, IEEE Transactions on Industry Applications, 52, 2436 2443 (2016).

5. S.S. Lee, M. Sidorov, C.S. Lim, N.R.N. Idris, Y.E. Heng, IEEE Transactions on Power Electronics, 33, 932-935 (2018).

6. H. Akagi, Proceedings of the IEEE, 105, 2048 2065 (2017).

7. K.K. Gupta, A.P. Ranjan, A. Bhatnagar , L.K. Sahu, S. Jain, IEEE Transactions on Power Electronics, 31, 135 - 151 (2016).

8. S.S. Lee, B. Chu, N.R.N. Idris, H.H. Goh, Y.E. Heng, IEEE Transactions on Industrial Electronics, 63, 2133 - 2142 (2016).

9. N. Susheela, P.S. Kumar, S.K. Sharma, IEEE Transactions on Industry Applications, 54, 2425 2437 (2018).

10. M. Schaefer, W. Goetze, M. Hofmann, F. Bayer, D. Montesinos-Miracle, A. Ackva, IEEE Transactions on Industrial Electronics, 64, 3067 - 3074 (2017).

11. S. Amamra, K. Meghriche, A. Cherifi, B. Francois, IEEE Transactions on Industrial Electronics, 64, 8855 - 8866 (2017).

12. O.J.K. Oghorada, L. Zhang, IEEE Transactions on Industrial Electronics, 66, 2891 - 2902 (2018).

13. H. Wang et al., IEEE Transactions on Industrial Electronics, 64, 7612 - 7622 (2017).

14. L. Wang et al., IEEE Journal of Emerging and Selected Topics in Power Electronics, 5, 841 - 853 (2017).

15. H. Wang, M. Su, Y. Sun et al., IET Power Electronics, 30, 657 - 668 (2016).

16. R. Li, J.E. Fletcher, B.W. Williams, IET Generation, Transmission \& Distribution, 10, 2764 - 2770 (2016).

17. S. Bifaretti, A. Lidozzi, L. Solero, F. Crescimbini, IEEE Transactions on Power Electronics, 31,6226 6236 (2016).

18. H. Wang et al., IEEE Transactions on Power Electronics, 31, 533 - 547 (2016).

19. P. Cheng, H. Nian, C. Wu, Z.Q. Zhu, IEEE Transactions on Power Electronics, 32, 284 - 297 (2017).

20. N. Sarma, P.M. Tuohy, J.M. Apsley, Y. Wang, S. Djurović, IET Renewable Power Generation, 12, 1366 - 1374 (2018).

21. C. Tu, J. Cao, L. He, Y. Fang, The Journal of Engineering, 2017, 2021 - 2025 (2017).

22. M.S. Marhaba, S. Farhangi, H. Iman-Eini, R. Iravani, IET Generation, Transmission \& Distribution, 12, 842 - 849 (2018).

23. H. Misra, A. Gundavarapu, A.K. Jain, IEEE Transactions on Industrial Electronics, 64, 2700 2708 (2017). 